\title{
OPEN SOURCE TECHNOLOGIES IN GEOGRAPHIC INFORMATION SYSTEMS
}

\author{
Marijana Petković' \\ Vladmir Bulatović, \\ Ivan Aleksić \\ ${ }^{1}$ University of Novi Sad, \\ Faculty of Technical Sciences, \\ Novi Sad, Serbia \\ 2University of Belgrade, \\ Faculty of Civil Engineering, \\ Belgrade, Serbia
}

\section{Correspondence:}

Marijana Petković

e-mail:

marijana.petkovic@uns.ac.rs

\begin{abstract}
:
During the last decade, a growing number of Free and Open Source Software (FOSS) projects have been established to focus on development of several types of software for geographic data collection, storage, analysis and visualization. Because GIS technologies are increasingly present in different applications, it is necessary to divide the existing software projects into categories based on their functions. The goal of this paper is to present an overview of mature free and Open Source software GIS Desktop software projects with their characteristics.
\end{abstract}

Key words:

free software, Open Source, FOSS, GIS, desktop GIS.

\section{INTRODUCTION}

In the last ten years, several software projects that focus on development of Free and Open Source Geographic Information Systems (GIS) software have been realized due to: the increased technological progress in automated mapping and monitoring, on-line distribution and faster and easier access to georeferenced data, etc. This field has evolved from a highly specialized niche to a technology with broad impact on society and its interaction with nature (Mitasova, 2002).

The number of exiting projects has not changed significantly but the changes are visible in software user and developer communities. The Open Source GIS projects have been able to attract users and developers, which has subsequently influenced software functionality and support and as a consequence raised their attractiveness to new potential users.

It is important to emphasize the role of Open Source GIS projects in education on the geodesy and geomatics studies. Open software, open data, open standards and open education are the key components of the proposed open GIS framework (Sui, 2014). Open education concepts, such as accessible teaching materials and the usage of free and Open Source software are all accessible. This enables students to become active community participants and gain spatial, critical thinking and problemsolving skills.

Our goal is to present an overview of (major) GIS software projects that develop Free and Open Source Software (FOSS), the classification of different types of GIS software, and a list and characteristics of most commonly used Desktop GIS software. 


\section{GEOGRAPHIC INFORMATION SYSTEM} (GIS)

There are several definitions of Geographic Information system (Goodchild, 2009), (Sween, 2008), (Camara, 2004), but the simplest told GIS is a technological tool for comprehending geography and making intelligent decisions from simple tasks as navigation to extremely complex tasks, such as prediction and management of natural disasters (ESRI, 2006). GIS technology is used to describe and characterize spatially referenced geographic information for the purpose of mapping, querying, visualizing, modeling and analyzing spatial data maintained within a single database. GIS is present in almost every industry and benefits organizations of all sizes. There is a growing interest and awareness of the economic and strategic value of GIS and it has evolved to be used in a multitude of disciplines.

\section{GIS software concept}

For a representation of geographic object in GIS, data representation has to be established first. GIS data can be separated into two categories: spatially referenced data which is represented by vector and raster forms (including imagery) and attribute tables which are represented in tabular format (Tsou, 2011). Vector data is divided into three types: polygon, line (or arc) and point data where every object is represented by a (vector) geometry and value fields that describe the non-spatial object properties, the so-called 'attributes', in a table. Raster data (also known as grid data) represents the fourth type of feature, surfaces. Surfaces represent variables that are continuous over space, such as terrain elevations or land cover. Geographic objects with same geometric and attribute representation are usually grouped into layers.

\section{Open Source and free GIS}

Open Source and Free Software (FOSS) GIS plays an important role in adaptation of GIS technology by stimulating new experimental approaches and providing access to GIS for the users who cannot or do not want to use proprietary products (Mitasova, 2002). The terms Free and Open Source Software are redundant but both are in use today (Sween, 2008). Both terms have the similar meaning, however the main difference is that free software could not be modified, and Open Source could.

The trend of Free and Open Source Software development, especially in the field of Geospatial Information
Systems (GIS), has grown rapidly in recent years. Open Source software is a type of "free" software to be accessed, used or modified by their user groups and developers (Sween, 2008).

Free Software Foundation (FSF) presents the following definition for Free software: "Free software is a matter of the user's freedom to run, copy, distribute, study, change and improve the software." The concept of Free Software was first defined by Richard M. Stallman and it refers to four kinds of freedom for the users of the software:

0 . Freedom The freedom to run the program, for any purpose.

1. Freedom The freedom to study how the program works, and adapt it to your needs. Access to the source code is a precondition for this.

2. Freedom The freedom to redistribute copies so you can help your neighbour.

3. Freedom The freedom to improve the program, and release your improvements to the public, so that the whole community benefits. Access to the source code is a precondition for this (Akbari, 2013).

The main reasons why a company should use Open Source and free software instead of proprietary software are:

- Easy access to (in many cases unique) functionality of high quality. Full access to the source code is particularly important for GIS because the underlying algorithms can be complex and can greatly influence the results of spatial analysis and modeling.

- No license costs reduce total development cost.

- Re-use of already tested components enhances the quality of the final product. (Sween, 2008)

\section{CATEGORIES OF GIS SOFTWARE}

GIS software is defined as software that is used to create, manage, analyze and visualize geographic data (Steiniger, 2009). First, the data need to be derived from field work, maps, satellite imagery, or acquired from data providers. Then, there are many tasks to be done to get the final product as:

- data visualization and exploration,

- data creation,

- data editing and data storage,

- data integration, data queries to select a subset of the data, 
- data analysis,

- data transformation, creation of maps for visualization of analysis and query results (Steiniger, 2009).

Depending on the set of tools that software provides, GIS software can be divided into several categories. Related Open Source software can be categorized into five domains for GIS:

1. Basic desktop GIS,

2. Spatial Data Base Management Systems (SDBMS),

3. Web Map Server,

4. Server GIS,

5. Web GIS clients,

6. Mobile GIS, Libraries and Extensions (Steiniger, 2009).

Figure 1 and Table 1 provide a summary of used categories of GIS software. Usually, desktop GIS applications can be divided by function into three groups: GIS Viewer, GIS Editor, and GIS Analyst. Spatial Database Management Systems (DBMS) allows user to create, read, update and delete spatial data in a database. Spatial DBMS also provide limited analysis and data manipulation functionality. Most often encountered are PostGIS, SpatiaLite and TerraLib. WebMap Servers like GeoServer, Mapink, MapServer are used for distribution of maps and data over the Internet, using Open Geospatial Consortium (OGC) standards Web Map Service (WMS) and Web Feature Service (WFS).

Data display and analysis and query functionalities are possible through WebGIS Clients. Libraries and Extensions are used to provide additional functionality which is not part of the basic GIS software. Mobile GIS is used for field data collection.

Most commonly used Desktop GIS software and some of their applications shall be presented. Other categories have been only briefly explained.

\begin{tabular}{|c|c|c|c|c|c|c|c|c|c|}
\hline $\begin{array}{l}\text { GIS tasks } \\
\text { software } \\
\text { category }\end{array}$ &. & : & 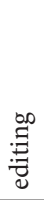 & \begin{tabular}{l}
$\stackrel{8}{0}$ \\
\multirow{2}{0}{} \\
$\stackrel{0}{\infty}$
\end{tabular} & 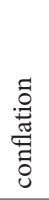 & 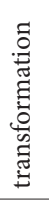 & $\begin{array}{l}\hat{d} \\
\vec{\sigma}\end{array}$ & 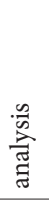 & 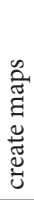 \\
\hline \multicolumn{10}{|l|}{ Desktop GIS } \\
\hline Viewer & ० & & & ○ & & & ○ & & $\Delta$ \\
\hline Editor & o & ○ & $\circ$ & ○ & & $\Delta$ & ○ & & ○ \\
\hline Analyst & o & o & ○ & o & o & 0 & o & o & o \\
\hline Spatial DBMS & & & & ० & & o & ० & $\diamond$ & \\
\hline WebMap Server & o & $\diamond$ & $\diamond$ & & & & O & & ० \\
\hline Server GIS & & & & ० & ० & o & ० & ० & ० \\
\hline \multicolumn{10}{|l|}{ WebGIS Client } \\
\hline Thin Client & 0 & & & & & & ० & & \\
\hline Thick Client & o & ○ & $\circ$ & O & & & O & ० & ○ \\
\hline Mobile GIS & o & ० & $\circ$ & O & & & 0 & & \\
\hline $\begin{array}{l}\text { Libraries/ } \\
\text { Extensions }\end{array}$ & & & & ○ & O & O & & O & O \\
\hline
\end{tabular}

Table 1. Funcionality of GIS tasks accomplished with different GIS software

$\circ$ standard functionality, $\diamond$ optional functionality

In addition to these categories, there is remote sensing software whose focus is on modification and geometrical and spectral transformation of aerial and satellite image data as well as Lidar data. Desktop GIS usually do not possess all the functionality needed for working with this type of data. Photogrammetric tools and remote sensing analysis tools for image correction and filtering, georeferencing and orthorectification, mosaicking and vectorization image object extraction are needed. There is smaller number of software projects for remote sensing than for GIS Desktop. Ossimo Project has been proved to be the most prominent one.

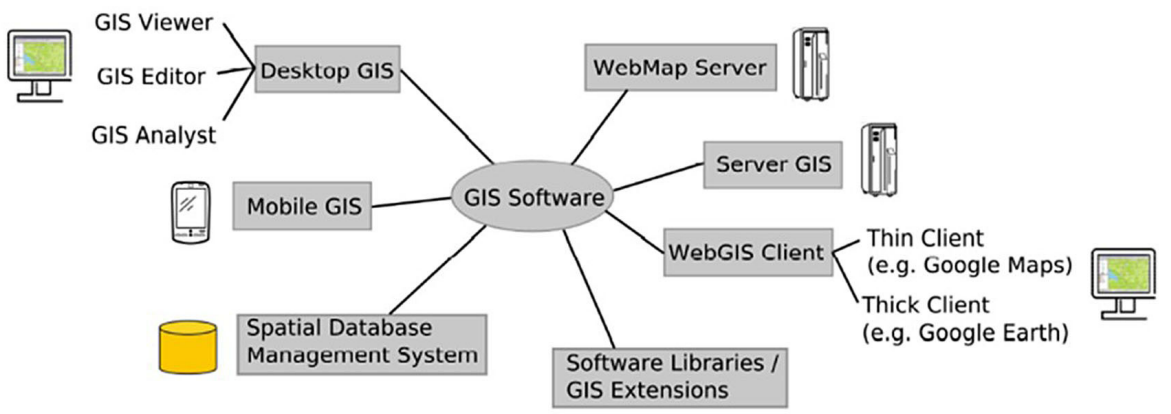

Figure 1. Different types of GIS software (Steiniger, 2009) 


\section{DESKTOP GIS}

Desktop GIS can be defined as mapping software that is installed onto and runs on a personal computer and allows users to display, query, update and analyze data about geographic locations and the information linked to those locations (Tsou, 2011). Most Open Source desktop GIS software can be installed on multiple operating systems (Windows, MacOS, Linux). However, the lack of advanced cartographic functions and symbolization may be a problem in Open Source

GIS software which is expected to be resolved soon in the future. There are many excellent Open Source software packages in the category of basic Desktop GIS.

In the case of 3 desktop GIS categories (viewer, editor, analyst), so-called viewer applications offer functionality for viewing and exploring data, while editor applications provide, in addition to viewer capabilities, the ability to create and update spatial data.

Software such as Spring GIS, Spatial Commander, Google Earth, Google Maps, ArcExplorer or TNTlite were not considered since these software products are free for download but not Free and Open Source Software (FOSS). All presented projects have reached a mature stage over the last few decades and the software offers a multitude of functionalities.

Open Source GIS software can also be categorized into groups based on the implementation language in which they were written. The most common programming languages are C and JAVA. UMN MapServer, GRASS, OSSIM, GEOS, PostGIS and QGIS were written in C while GeoTools, uDig, GeoServer, JUMP, and DeeGree were written in JAVA (Ramsey, 2007).

Many of these projects base their activities related to the development of software on the limited range of functionality, so the problem occurs that certain actions can been done with more than one desktop GIS software. Therefore, gvSIG Community Edition project was formed to bundles to a gvSIG, GRASS and SAGA in one distribution.

\section{Geographic Resources Analysis Support System (GRASS)}

Geographic Resources Analysis Support System (GRASS) is one of the biggest Open Source GIS projects realized under GNU GPL (General Public License). During the past 30 years, GRASS has formed a very large and active community of users and developers. The software combines different engines for raster, vectors and spatial processing and provides a wide range of tools for spatial analysis, modeling, image/ recording processing and visualization. $2 \mathrm{D}$ raster/voxel display and analysis, $2 \mathrm{D} / 3 \mathrm{D}$ vector editing, vector network analysis and image processing functions are supported. It has proven as a great choice for generating Digital Terrain Models (DMT) as shown in Figure 2. The functionality given in this software can be compared to that of commercial software ESRI's ArcGIS on the ArcInfo level (Steinger, 2009).

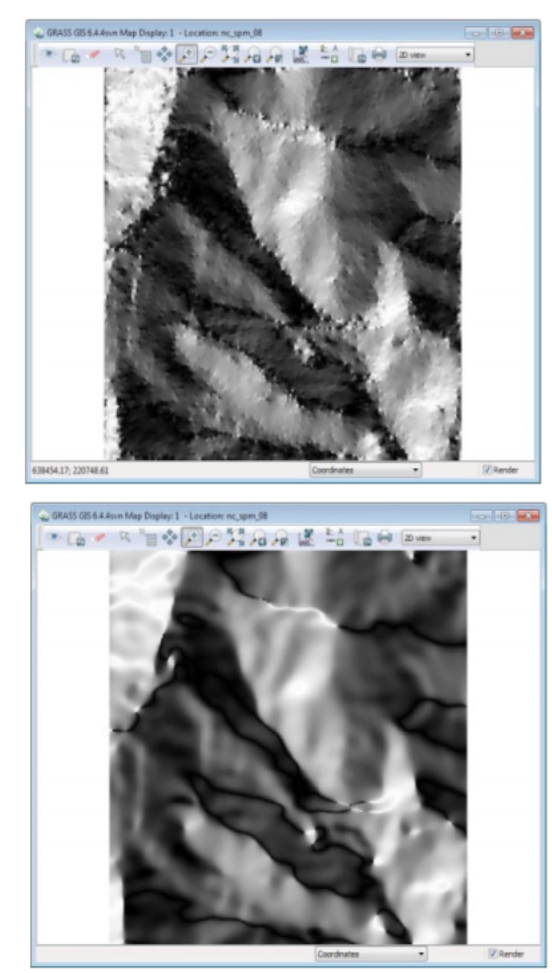

Figure 2. DTM in GRASS

GRASS can import a wide range of formats and has the ability to directly read attribute and spatial data from PostGIS. Quantum GIS can embed all GRASS functions via a graphic user interface (GUI) for easier public use. Multiple data input formats are available (Tsou, 2011). GRASS has been mostly used as an effective modeling tool which can carry out complex data analysis (Ramsey, 2007).

GRASS also provide modeling and simulations for hydrology, erosion, pollution and fire speed, which is why this software is being used in different applications related to risk management. Processing aerial survey data using GIS can also be done with GRASS.

\section{Quantum GIS (QGIS)}

Quantum GIS (QGIS) allows users to create maps with many layers using different map projections and it 
represents a great tool for spatial data viewing, editing, and analysis.

QGIS is integrated with other open- source GIS packages, including PostGIS, GRASS and MapServer to give users extensive functionality. Plugins written in Python or C++ extend QGIS's capabilities and allow users customization or automatization of GIS functions (Tsou, 2011). Python is a widely used and supported Open Source programming language that is both powerful and easy to learn and it is also adopted by ESRI ArcGIS for their programming functions.

There are many different versions of QGIS available for download. Useful GIS tools are suitable for different spatial analysis, data management, geometry and geoprocessing. QGIS possesses an interface designed for GIS users and allows easy spatial data management. Adding layers to different types of data is done via the icons on the left side of the interface. Different models and simulations are supported.

The software provides the support of DWG file formats and the linkages to GRASS functionalities and to Web (WMS, WFS). ESRI shapefiles and coverage formats are supported. QGIS supports PostGIS and Shapefiles as vector data sources. QGIS supports DEM, ArcGrid, ERDAS, SDTS, and GeoTIFF raster formats (Ramsey, 2007).

\section{User-friendly Desktop Internet GIS (uDIG)}

uDig is a great Desktop GIS choice for access, editing and viewing software built on Java. Interface is user friendly, so uDig provide a familiar graphical environment for GIS users which facilitate manipulation with spatial data.

Therefore, uDig offers strong capabilities to integrate Web mapping technologies, standards, framework, printing support, standard GIS file format, coordinate projection support, database access support, cross-platform support, customizability, modularity and thematic mapping with advanced symbology (Ramsey, 2007).

Loading existing vector, raster and tabular data is done by simply adding these files into layers. A large number of data sources is supported, which can be seen in Figure 4. It is further possible to manipulate with attributes and formation of requested solutions.

\section{JUMP, OPEN JUMP, KOSMO}

JUMP represents a very useful user interface toolkit for visualization. JUMP has a specific position in the community as several forks (i.e. child products) emerged when the initial development stopped.

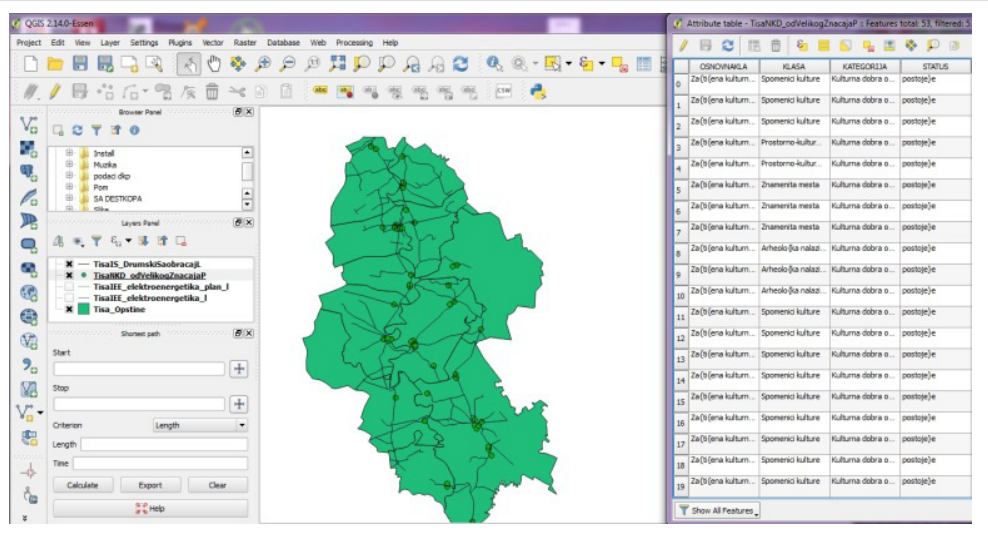

Figure 3.Vector data in QGIS

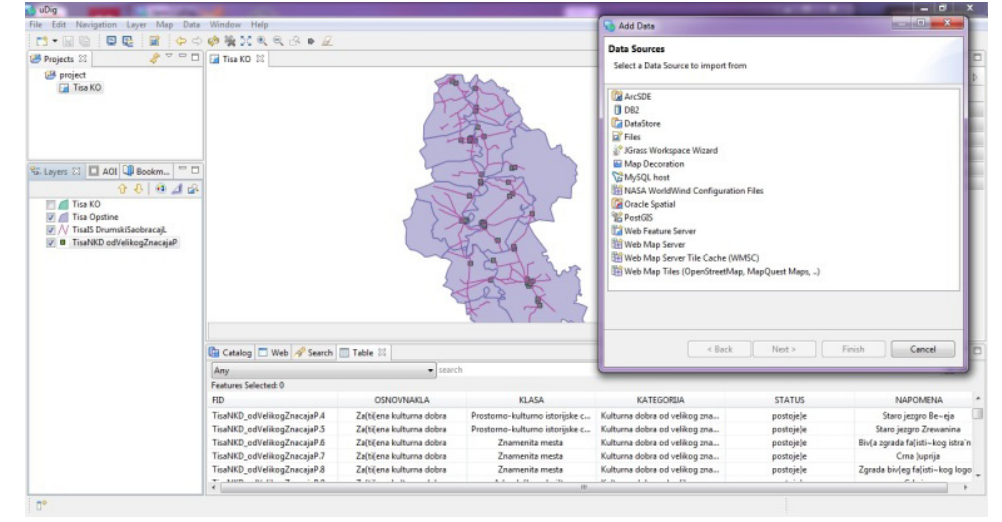

Figure 4. Vector data in uDig 
KOSMO is one of the most popular Open Source desktop GIS with nice Graphic User Interface (GUI), GIS data editing tools, and spatial analysis functions (Tsou, 2011). KOSMO is one of the original JUMP GIS fork and was developed based upon OpenJUMP (Steinger, 2009). KOSMO has improved cartographic and spatial analysis functions, which provide a friendly and comprehensive GIS package for desktop computers. The major advantage is the capability for users to edit/modify vertices in vector-based layers. JUMP supports GML, Shape and RDBMS data sources.

$$
g v S I G
$$

gvSIG was developed by the European GIS community offering multiple language user interfaces (more than ten different languages) with flexible GIS data input format. Various GIS data formats (both vector and raster) and online resources can be used.

Today gvSIG is considered as a powerful Spatial Data Infrastructures (SDI) client that enables the connection to OGC Services like WMS, WFS, and WCS. Those standards allow users different functionalities for accessing data, overlapping it and combining it in gvSIG map views. gvSIG contains functions for good vector data editing (Alvaro, 2008).

Some GIS professionals believe that gvSIG is becoming close to replacing ESRI ArcMap software (Tsou, 2011). gvSIG, as a desktop environment, contains all the core functionality for styling, printing with layouts, data editing, raster and vector data support. The idea for gvSIG was to become "all-in" application for all GIS users at all levels. gvSIG offers integration of CAD and GIS worlds, vector and raster, local data with SDI and 2D with 3D and 4D.

\section{A comparative analysis}

Each of the listed software solutions has its own advantages and disadvantages. Table 2 gives an overview of the functionality they possess. The first partition of functionality column is concerned with data access (reading and writing) and refers to possibility to use the existing formats. Manipulation of vectors involves working with vector data, their creation, basic and advanced functions. The analysis grid is divided into working with $2 \mathrm{D}$ and 3D data and visualization i.e. display. Standard concerns OGC and ISO standards that are supported.

\begin{tabular}{|c|c|c|c|c|c|c|}
\hline & & 㤐 & $\stackrel{\mathscr{J}}{0}$ & $\stackrel{.0}{\exists}$ & 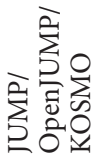 & 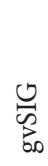 \\
\hline \multirow{4}{*}{$\begin{array}{l}\text { Data access } \\
\text { (Read/Write) }\end{array}$} & Raster & $\sqrt{ }$ & $\sqrt{ }$ & $\sqrt{ }$ & $\sqrt{ }$ & $\sqrt{ }$ \\
\hline & Vector & $\sqrt{ }$ & $\sqrt{ }$ & $\sqrt{ }$ & $\sqrt{ }$ & $\sqrt{ }$ \\
\hline & Table & $\sqrt{ }$ & $\sqrt{ }$ & - & $\sqrt{ }$ & $\sqrt{ }$ \\
\hline & Database & $\sqrt{ }$ & $\sqrt{ }$ & $\sqrt{ }$ & $\sqrt{ }$ & $\sqrt{ }$ \\
\hline \multirow{5}{*}{$\begin{array}{l}\text { Vector ma- } \\
\text { nipulation }\end{array}$} & Create, Edit & $\sqrt{ }$ & $\sqrt{ }$ & $\sqrt{ }$ & $\sqrt{ }$ & $\sqrt{ }$ \\
\hline & Basic tools & $\sqrt{ }$ & $\sqrt{ }$ & $\sqrt{ }$ & $\sqrt{ }$ & $\sqrt{ }$ \\
\hline & $\begin{array}{l}\text { Advance 2D } \\
\text { analysis }\end{array}$ & $\sqrt{ }$ & $\sqrt{ }$ & $\sqrt{ }$ & $\sqrt{ }$ & $\sqrt{ }$ \\
\hline & 3D analysis & $\sqrt{ }$ & $\sqrt{ }$ & - & - & $\sqrt{ }$ \\
\hline & $\begin{array}{c}\text { Topology sup- } \\
\text { port }\end{array}$ & $\sqrt{ }$ & $\sqrt{ }$ & - & $\sqrt{ }$ & - \\
\hline \multirow{2}{*}{$\begin{array}{l}\text { Raster } \\
\text { analysis }\end{array}$} & $2 \mathrm{D}$ & $\sqrt{ }$ & $\sqrt{ }$ & - & - & $\sqrt{ }$ \\
\hline & $3 \mathrm{D}$ & $\sqrt{ }$ & $\sqrt{ }$ & - & - & $\sqrt{ }$ \\
\hline \multirow{2}{*}{ Visualization- } & $2 \mathrm{D}$ & $\sqrt{ }$ & $\sqrt{ }$ & $\sqrt{ }$ & $\sqrt{ }$ & $\sqrt{ }$ \\
\hline & $3 \mathrm{D}$ & $\sqrt{ }$ & - & - & - & $\sqrt{ }$ \\
\hline \multirow{2}{*}{ Appearance - } & Styling & $\sqrt{ }$ & $\sqrt{ }$ & $\sqrt{ }$ & $\sqrt{ }$ & $\sqrt{ }$ \\
\hline & Labelling & $\sqrt{ }$ & $\sqrt{ }$ & $\sqrt{ }$ & $\sqrt{ }$ & $\sqrt{ }$ \\
\hline \multicolumn{2}{|c|}{ Temporal analysis } & $\sqrt{ }$ & $\sqrt{ }$ & - & - & - \\
\hline \multicolumn{2}{|c|}{ Modular (Pluginable) } & $\sqrt{ }$ & $\sqrt{ }$ & $\sqrt{ }$ & $\sqrt{ }$ & $\sqrt{ }$ \\
\hline \multicolumn{2}{|c|}{ Standard } & 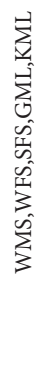 & 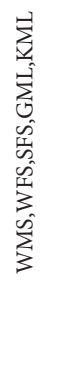 & 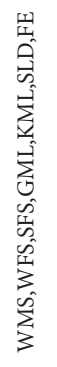 & 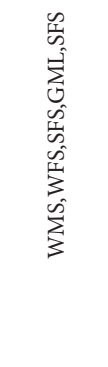 & 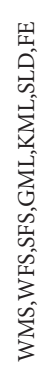 \\
\hline
\end{tabular}

Table 2. The result of comparing desktop gis software

\section{CONCLUSION}

Although private GIS software companies such as ESRI, Microsoft, Google and Intergraph had the biggest role in GIS development in the past, GIS Open Source Software Society has been providing good software solutions and is considered a strong competitor today. There is an increasing level of collaboration among Open Source projects today to ensure the creation of better quality GIS solutions. 
Using Open Source GIS software proved to be very suitable at different levels (education, research and professional) due to their cost effectiveness and ease of use.

Certain common misconceptions exist today about the Open Source GIS software. Open Source GIS software solutions have robust capabilities for geospatial database creation, spatial analysis and geospatial web applications. They are compatible, substandard compared to proprietary software and they do have commercial support. Open Source software can be a replacement for or a compliment to commercial software.

For almost every geospatial software need and niche there is at least one mature Free and Open Source Software project with a well-documented record of successful application in diverse applications.

There are numerous Open Sources solutions at disposal depending on the needs of modern GIS clients. Open Source software projects are usually concentrated on one category, e. g. GIS desktop or WebMap Server while products by commercial vendors are for more than one category. Free desktop GIS projects, such as Quantum GIS and gvSIG, currently experience growing user communities. From data analysis view point GRASS has been proven as efficient software.

\section{REFERENCES}

Akbari, M., \& Mohammad, A. R. (2013). Evaluation of desktop free/Open Source GIS software based on functional and non-functional capabilities. Tehnickivjesnik/Technical Gazette, Volume 20.5, 755-764.

Alvaro, A., \& Díaz L. (2008). gvSIG: A GIS desktop solution for an open SDI. Journal of Geography and Regional Planning, Volume 1.3, 041-048.

Câmara, G., \& Harlan, O. (2004). Open-source geographic information systems software: myths and realities. In Open Access and the Public Domain in Digital Data and Information for Science: Proceedings of an International Symposium. Washington, DC: The national Academies Press.
Goodchild, M. (2009). Geographic Information System. In L. Liu, \& M.T Zsu, Encyclopedia of Database Systems (pp. 1231-1236). New York, USA: Springer US.

Environmental Systems Research Institute (ESRI). (2006). ArcGIS, ver. 9.2: ESRI, Retrieved March 24, 2016, from http://www.esri.com/software/arcgis/index.html

Mitasova, H., \& Markus, N. (2002). Freedom in geoinformation science and software development: A GRASS GIS contribution. In Open Source Free Software GIS-GRASS users Conference. 11-13 September 2002. Trento, Italy.

Ramsey, P. (2007). The state of Open Source GIS, Refractions Research.Retrieved March 24, 2016, from http://www.refractions.net/expertise/whitepapers/ opensourcesurvey/survey-open-source-2007-12.pdf.

Steiniger, S., \& Erwan B. (2009). An overview on current free and Open Source desktop GIS developments. International Journal of Geographical Information Science, Volume 23.10, 1345-1370, DOI: 10.1080/13658810802634956.

Sveen, A. F. (2008). Use of free and Open Source GIS in commercial firms.Retrieved March 24, 2016, fromhttp://www.atlefren.net/wordpress/wp-content/uploads/2009/03/fos_gis_af_sveen_web_cc-by-nd.pdf.

Tsou, M. H., \& Smith J. (2011). Free and Open Source software for GIS education. Retrieved March 24, 2016, from http://geoinfo.sdsu.edu/hightech/WhitePaper/tsou_free-GIS-for-educators-whitepaper.pdf.

Steiniger, S., \&Weibel, R., (2009). GIS software - a description in 1000 words. Retrieved March 24, 2016, fromhttp://www.zora.uzh.ch/41354/1/Steiniger Weibel_GIS_Software_2010.pdf.

Sui, D. (2014). Opportunities and Impediments for Open GIS. Transactions in GIS.Volume 18.1, 1-24. DOI:10.1111/ tgis.12075. 